\title{
Neurofibromatosis in pregnancy: study of 2 cases
}

\author{
Khushboo Jain $^{1 *}$, Mamta Sharma ${ }^{1}$, Hitesh Mangal $^{2}$ \\ ${ }^{1}$ Department of Obstetrics \& Gynaecology, Government Medical College, Kota, Rajasthan, India \\ ${ }^{2}$ Department of Orthopaedics, Government Medical College, Kota, Rajasthan, India
}

Received: 07 January 2015

Accepted: 14 February 2015

\section{*Correspondence:}

Dr. Khushboo Jain,

E-mail: jaindrkhushboo@gmail.com

Copyright: ( $)$ the author(s), publisher and licensee Medip Academy. This is an open-access article distributed under the terms of the Creative Commons Attribution Non-Commercial License, which permits unrestricted non-commercial use, distribution, and reproduction in any medium, provided the original work is properly cited.

\begin{abstract}
The report presents two cases of neurofibromatosis (NF) and illustrates how women with NF have increased complications associated with pregnancy. With these case reports, we wanted to describe the diagnostic possibilities, management of pregnancies and dilemmas in everyday clinical practice of a gynaecologist.
\end{abstract}

Keywords: Pregnancy, Neurofibromatosis, Placenta praevia

\section{INTRODUCTION}

Neurofibromatosi (NF) is one of the most common genetic disorders associated with an incidence of 1 in 3500 live births. It is an autosomal dominant condition with a wide range of clinical manifestations. The aim of the study was to assess the maternal \& perinatal outcome in pregnant patients with NF. Our cases add to the literature on aggravation of neurofibromatosis in pregnancy and higher chance of complications in pregnancy with NF.

\section{CASE REPORT}

Two cases of pregnancy with NF were reported in a span of 1 year from Aug 2013 to July 2014 among 12439 deliveries.

First case was a 25 year old woman who was referred to emergency as a case of NF with APH and PIH. She was G3P2L2A0.

On examination general condition was average; she was afebrile with pallor \& icterus present. There were multiple big \&small fibromas all over the body. She had a history of regression of neurofibromas after delivery \& flaring up of lesions during pregnancy .Her family history was insignificant. Her BP was 140/100 pulse 96/min. On per abdomen examination uterus was 32 weeks, FHS+R, cephalic and uterus was not acting and not tense \& tender. On per speculum examination bleeding per vagina was present.

Ultra sound examination showed 32 weeks placenta praevia grade III with severe oligohydramnios, AFI $3 \mathrm{~cm}$ \& cholelithiasis. Hb\%: 9.6 gm\%, BT: $2.11 \mathrm{~min}, \mathrm{CT}: 4.15$ min, ABORh: B+, S.bilirubin: 10mg/dl, SGOT: 140, SGPT: 183 \& urine albumin was trace. RFT \& Fundoscopy were normal.

On account of bleeding placenta praevia pregnancy was terminated by caesarian section and a preterm neonate of $2 \mathrm{~kg}$ with APGAR score $6 / 7$ at $1 / 5 \mathrm{~min}$ was born which was immediately admitted in NICU. On discharge the patient was referred to gastroenterologist for obstructive jaundice for ERCP.

The other patient was a 35 year old G5P2L2A2, who presented for the first time in emergency with labour 
pains. On enquiring about the dates she was post-dated by 2 days.

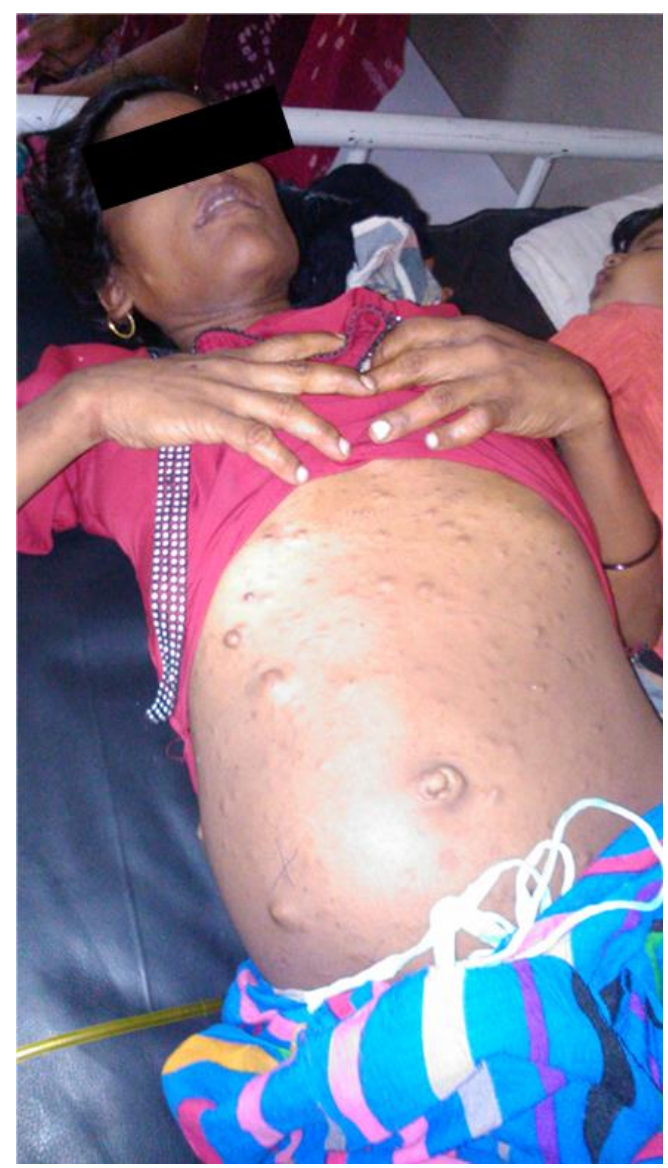

Figure 1: Case no.1.

On examination general condition was average. She had numerous large and small neurofibromas all over the body with a big plexiform mass hanging out from right eye. Her BP was $120 / 80 \mathrm{mmHg}$, pulse $88 / \mathrm{min}$. On per abdomen uterus term size, FHS + R, cephalic, uterus mildly acting. On per vaginum os one finger, started taken up, membranes + , vertex at -3 stn.

Dinoprostone gel was introduced for augmentation of labour. After 48 hours also there was no progress so caesarean was decided with failed induction and postdatism .A healthy female child was born.

On fourth postop day she developed fits which were GTCS in nature. She was normotensive and urine albumin was nil. Neurophysician reference was done who advised loading dose of phenytoin followed by maintenance dose and CT scan head was done which showed a space occupying lesion meningioma. She was discharged on tab phenytoin and referred to neurosurgeon after which she lost follow up.

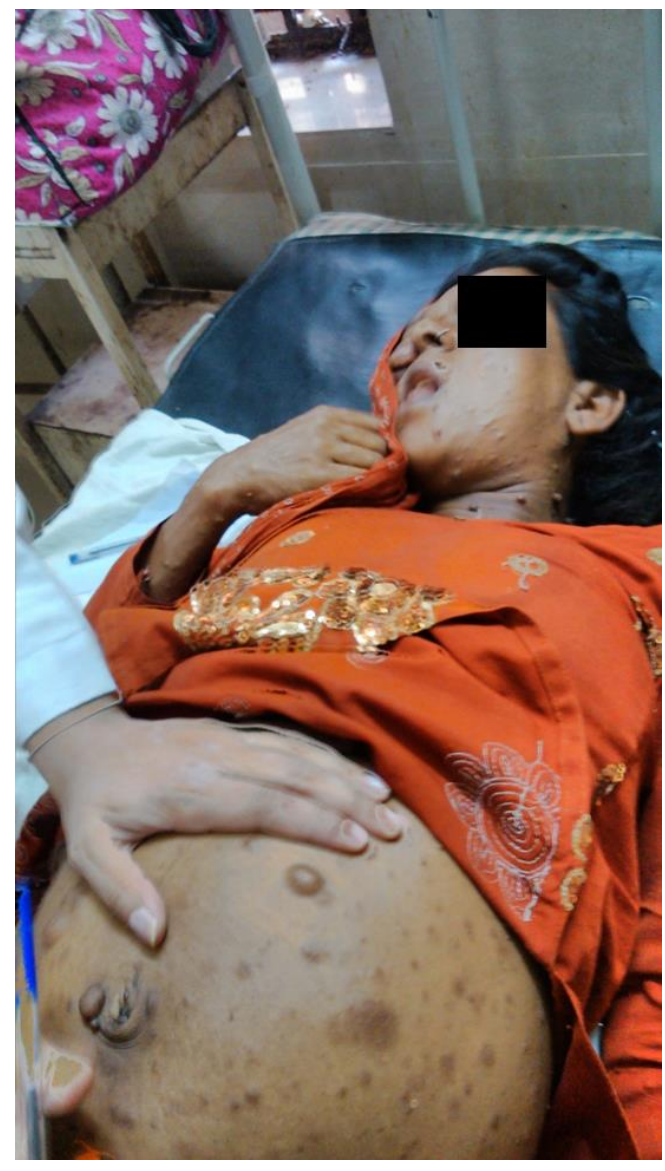

Figure 2: Case no. 2.

\section{DISCUSSION}

$\mathrm{NF}$ is a type of neurocutaneous syndrome (Phakomatoses) which are genetic disorders characterized by cutaneous lesions \& increased risk of brain tumor.

NF-I (von Recklinghausen's disease) is an autosomal dominant disorder with incidence of 1 in 3500, approximately half cases are familial, remainder are new mutations arising in patients with unaffected parents. NFI gene is present on chromosome $17 \mathrm{q}$ codes for a huge protein neurofibromin, a GTPase activating protein (GAP) that modulates signalling through Ras pathway. Mutations in NF-I gene result in a large number of nervous system tumors including neurofibromas, plexiform neurofibroma, optic nerve gliomas, strocytomas, meningiomas. In addition to neurofibromas which appear as multiple, soft rubbery cutaneous tumors, other cutaneous manifestations include café-au-lait spots and axillary freckling. NF-I is also associated with hamartomas of the iris -LISCH nodules, pheochromocytomas, pseudoarthrosis of tibia, scoliosis, epilepsy and mental retardation. ${ }^{1}$

NF-II is less common than NF-I with an incidence of 25000-40000. It is also an autosomal dominant condition. NF-II gene present on chromosome $22 \mathrm{q}$ encodes a cytoskeletal protein MERLIN that functions as a tumor 
suppressor. NF-II is characterized by bilateral vestibular schwannomas in over $90 \%$ patients, multiple meningiomas, spinal ependymomas and astrocytomas.

Many authors have suggested that pregnancy complications were more common in women with NF-III. NF has increased risk of complications like spontaneous miscarriages, preterm delivery, pre-eclampsia, IUGR, still birth \& HELLP syndrome as well as maternal disease aggravation. ${ }^{4}$

It has increased frequency of obstetric disease there by placing these women and their fetus at risk.

An increased incidence of caesarian section is also reported which could be due to fetal distress, malpresentation and CPD.

Some recommend early termination of pregnancy because of adverse effect of pregnancy on the course of the disease \& poor pregnancy outcome.

Neurofibromas which are the hallmark, enlarge and many new lesions appear for the first time during pregnancy. This could be due to haemorrhage within the masses or lysophosphatidic acid mediated promotion of $\mathrm{F}$ actin polymeristion with increase migration and survival of Schwann cells. With respect to NF-I changes during pregnancy, the majority of women report the development of new neurofibromas, growth of existing ones or both, indicating that pregnancy may promote neurofibroma growth. ${ }^{5}$

\section{CONCLUSIONS}

In our cases patient reported in late pregnancy with obstetric complications so management was individualized but, if patient comes in early pregnancy we are obliged to make as accurate prenatal diagnosis as possible, through linkage analysis of family member \& direct characterization of gene mutations..

Funding: No funding sources

Conflict of interest: None declared

Ethical approval: Not required

\section{REFERENCES}

1. Strom CM, Strom S, Levine E, Ginsberg N, Barton J, Verlinsky Y. Obstetric outcomes in 102 pregnancies after preimplantation genetic diagnosis.Am J Obstet Gynecol. 2000;182(6):1629-32..

2. Origone P, Bonioli E, Panucci E, Costabel S, Ajmar F,Coviello DA. The Genoa experience of prenatal diagnosis in NF1. Prenatal Diagnosis. 2000;20(9):719-24.

3. Posma E, Aalbers R, Kurniawan YS, van Essen AJ, Peeters PM, van Loon AJ. Neurofibromatosis type I and pregnancy: a fatal attraction? Development of malignant schwannoma during pregnancy in a patient with neurofibromatosis type I. BJOG. 2003;110(5):530-2.

4. Isikoglu M, Has R, Korkmaz D,Bebek N. Plexiform neurofibroma during and after pregnancy. Arch Gynecol Obstet. 2002;267(1):41-2.

5. Nebesio TD, Ming W, Chen S, Clegg T, Yuan J, Yang Y, et al. Neurofibromin-deficient Schwann cells have increased lysophosphatidic acid dependent survival and migration-implications for increased neurofibroma formation during pregnancy. Glia. 2007;55(5):527-36.

DOI: $10.5455 / 2320-1770$. ijrcog20150441

Cite this article as: Jain $\mathrm{K}$, Sharma M, Mangal $\mathrm{H}$.

Neurofibromatosis in pregnancy-study of 2 cases. Int J Reprod Contracept Obstet Gynecol 2015;4:483-5. 